\title{
Hantavirus disease (nephropathia epidemica) in Belgium: effects of tree seed production and climate
}

\author{
K. TERSAGO ${ }^{*}$, R. VERHAGEN ${ }^{1}$, A. SERVAIS ${ }^{2}$, P. HEYMAN ${ }^{3}$, G. DUCOFFRE \\ AND H. LEIRS ${ }^{1,5}$ \\ ${ }^{1}$ Department of Biology, Evolutionary Ecology group, University of Antwerp, Antwerp, Belgium \\ ${ }^{2}$ Comptoir Wallon des Matériels Forestiers de Reproduction, Marche-en-Famenne, Belgium \\ ${ }^{3}$ Research Laboratory of Vector-Borne Diseases, Queen Astrid Military Hospital, Brussels, Belgium \\ ${ }^{4}$ Scientific Institute of Public Health, Epidemiology Unit, Brussels, Belgium \\ ${ }^{5}$ Danish Pest Infestation Laboratory, Department of Integrated Pest Management, Faculty of Agricultural \\ Sciences, University of Aarhus, Denmark
}

(Accepted 2 June 2008)

\section{SUMMARY}

Recently, human cases of nephropathia epidemica (NE) due to Puumala virus infection in Europe have increased. Following the hypothesis that high reservoir host abundance induces higher transmission rates to humans, explanations for this altered epidemiology must be sought in factors that cause bank vole (Myodes glareolus) abundance peaks. In Western Europe, these abundance peaks are often related to high tree seed production, which is supposedly triggered by specific weather conditions. We evaluated the relationship between tree seed production, climate and NE incidence in Belgium and show that NE epidemics are indeed preceded by abundant tree seed production. Moreover, a direct link between climate and NE incidence is found. High summer and autumn temperatures, 2 years and 1 year respectively before NE occurrence, relate to high NE incidence. This enables early forecasting of NE outbreaks. Since future climate change scenarios predict higher temperatures in Europe, we should regard Puumala virus as an increasing health threat.

Key words: Climate, ecology, epidemiology, hantavirus infection, Myodes glareolus, Puumala virus, seed production.

\section{INTRODUCTION}

Many zoonoses are listed as recent emerging or re-emerging infectious diseases [1]. Often it is the synergistic relationship between anthropogenic and ecological parameters which leads to an increased number of reported infections. Recently, 15 emerging

\footnotetext{
* Author for correspondence: K. Tersago, University of Antwerp, Department of Biology, Evolutionary Ecology Group, Groenenborgerlaan 171, 2020 Antwerp, Belgium.

(Email: Katrien.Tersago@ua.ac.be)
}

endemic zoonoses with potential human health risks were reported within Europe during the period 2000-2006 and most of these zoonoses were related to changes in ecological variables, e.g. increasing host population abundance, climate change or host migration [2,3]. The rodent-borne hantaviruses (genus Hantavirus, family Bunyaviridae) are part of this list, partly due to the abrupt increase in nephropathia epidemica (NE) incidence during 2005 in Belgium, Germany, France, Luxembourg and The Netherlands $[4,5]$. NE, caused by Puumala virus (PUUV) 
infection, is a widespread zoonosis throughout Europe. The disease is marked by a range of symptoms going from abrupt onset of fever and headache towards vomiting and acute renal failure [6]. The distribution of NE is mostly related to the occurrence of the predominant reservoir host Myodes glareolus (bank vole). The virus is transmitted among bank voles through virus particles shed in their excretions. Transmission occurs directly through aggressive or sexual contacts among voles or indirectly by inhaling virus aerosols originated from contaminated urine or faeces. The latter is also assumed to be the main transmission route to accidental hosts, e.g. humans, who are, as far as we know, dead-end hosts. If humans get infected with PUUV, it can take up to several weeks to develop symptoms due to PUUV infection [6].

In the present study, we focus on NE in Belgium. A distinct difference in $\mathrm{NE}$ incidence is present throughout this small country with rare occurrence of $\mathrm{NE}$ in the north, yet high incidences in south Belgium [7, 8]. Additionally, there is a lot of annual variation between 'epidemic' and 'non-epidemic' years. Until 2000 a 3-year epidemic cycle was described, after which it abruptly changed into a 2-year cycle that currently remains [5, 7]. Furthermore, in 2005, 365 human cases were reported, this was the highest incidence ever recorded after the 1996 outbreak (224 cases). Previous studies have shown that environmental conditions which favour the indirect transmission route, combined with specific human activities, could play a major role in explaining the spatial distribution patterns of both bank vole and human infection [8-10]. Temporal variation in PUUV infection risk, however, was rarely assessed. When it comes to actual risk of infection as previously described [11], it is hypothesized that it is the abundance of infected voles at a given time that remains predominantly crucial. This seems to hold as increased densities of infected bank voles have been related to outbreak years on several occasions [9, 12]. A recent model, however, suggests importance of the abundance of 'newly' infected voles [13], due to the higher rate of infectious virus shedding in their excretions [14]. Thus the model states that only extreme changes in bank vole demography can affect PUUV infection risk towards humans. Rodent dynamics are influenced by many aspects in the environment. Unlike the situation in Northern Europe where high bank vole abundance is mostly explained by density-dependent effects on predators and vole maturation [15], major peaks in bank vole abundance in the West-Central European region have almost solely been related to mast years in tree seed production [16-19]. High seed production affects bank vole abundance in several ways. It can improve winter survival, elongate the bank vole breeding period and even induce winter breeding [17-19]. Reproduction of bank voles is regulated by a densitydependent process involving social interaction and occupancy of female breeding territories. In case of high resource availability, female territories become smaller. Hence, during high tree seed production, new unoccupied territories are created in autumn. As a consequence, young female subadults, who would normally delay breeding until the next spring, will still be able to acquire their own breeding territory and initiate reproduction in autumn. Due to the synergistic effect of higher winter survival, extension of the breeding period and a high proportion of breeding females, the population density can remain high until the next spring [17-21]. It is generally believed that rodent peaks are caused by massive production of seeds by native oak or beech and relate to subsequent $\mathrm{NE}$ outbreaks in Belgium [7, 12, 22], although this was never thoroughly investigated. Furthermore, if tree seeding is indeed the driving force behind NE outbreaks in Belgium, the ultimate explanations for the recent patterns in NE epidemiology must be sought in those factors that trigger tree seed production. Forestry studies indicate that, in case of sufficient tree resources, it is mainly climate that affects tree fructification. For Fagus sylvatica, Quercus robur and $Q$. petraea there is a period of dormancy between flower bud initiation (early summer/summer) and flowering (pollination)/seeding (respectively spring and autumn in the following year). Both flower bud induction and flowering (pollination) can be affected by local weather conditions and there is no overall consensus on the dominant factors due to inter-species differences [23-25]. Only one factor seems to be consistent through most of the literature and that is summer conditions. Especially for beech there is a general agreement that warm or dry summer conditions during flower bud formation is a predominant factor for high seed production in the next year $[25,26]$. Climate conditions during high bank vole abundances, however, can also affect human behaviour and transmission to humans as humid and colder conditions could lead to better survival of the virus in the surroundings, hence, increasing the probability of transmission between voles and to humans $[8,27]$. 
The aim of this study is first to evaluate the relationship between NE numbers and categories of tree seed production in Belgium. Second, to test whether known climatic factors that trigger high seed production can be directly related to human NE incidence or if climatic conditions during the period of human infection cause a higher number of NE cases.

\section{METHODS}

\section{NE data}

NE data were provided by the Scientific Institute of Public Health (IPH) and the Reference Laboratory for hantavirus infection. The surveillance of human hantavirus infections in Belgium is carried out through a network of sentinel laboratories, coordinated by the IPH. These sentinel laboratories send positive samples to the Reference Laboratory for confirmation. Reliable annual NE case numbers are available from 1994 until 2007.

\section{Tree seed production categories}

Categories of seed production of beech and native oak species $(Q$. robur, $Q$. petraea $)$ were provided by the Tree Seed Centre of the Ministry of the Walloon Region. Since 1995, this centre has collected seeds for economic purposes. Due to their access to independent information sources, they are able to make reliable global assessments of tree seed production throughout southern Belgium. These assessments are based on tree flowering, pollination and seed production evaluations in the field, which are related to information from the forest service that gives the potential of seed collection in their selected stands. Tree seed production for each tree species is divided into four categories. Very good years (the species is fruiting throughout the Walloon territory and practically all trees are bearing seed in high quantities), Good years (the species is fruiting throughout the territory, but the trees are bearing much less seed and some trees do not fruit), Moderate years (there is a reduced number of trees bearing seeds and sometimes only located in a portion of the territory) and Low years (years without fructification in significant quantities).

\section{Climate data}

The meteorogical data were provided by the Royal Meteorological Institute from Belgium (Ukkel).
Average monthly and seasonal temperature and precipitation values were calculated from daily weather data. Meteorological seasons were used: winter (December, January, February), spring (March, April, May), summer (June, July, August), autumn (September, October, November).

\section{Statistical analyses}

Generalized Linear Models (GLM) in SAS ${ }^{\circledR}$ version 9.1 [28] were used to investigate the effect of beech and native oak tree seed categories on the number of NE cases in the following year. Log-linear models with $\log$ link function and both a Poisson and negative binomial distribution were compared using the likelihood ratio model comparison method [29]. The model with a negative binomial error distribution fitted our data significantly better $(P<0 \cdot 001)$. Pairwise comparisons were assessed using least square means.

Similar GLM analyses were used to evaluate the relationship between annual NE occurrence in year $t$ and ecologically relevant monthly and seasonal values of average daily temperature and precipitation from summer of year $t-3$ until autumn of year $t$. Monthly data were only used for those months or combinations that have been shown to be ecologically relevant in previous studies; June-July (year $t-2$ ), June-July (year $t-3$ ), July (year $t-2$ ), April (year $t-1$ ), May (year $t-1$ ), June (year $t-2$ ), June (year $t-3$ ), July (year $t-2$ ), July (year $t-3$ ), September (year $t-2)$ [17, 23-26].

To take into account first-order autocorrelation, the effect of the preceding year $t-1$ number of NE cases was added to the model and independence among explanatory variables was tested using Spearman correlations. All variables were modelled in loglinear models with $\log$ link function and both a Poisson and negative binomial distribution. Again, likelihood ratio model comparison showed that models with a negative binomial response distribution fitted best $(P<0 \cdot 001)$. Overall results however did not differ significantly. Final model selection was based on AIC (Akaike Information Criterion) statistics [29].

\section{RESULTS}

\section{Variation in NE case numbers and tree seed production}

Figure 1 shows the number of human PUUV cases (NE) from 1995 to 2007, demonstrating an abrupt increase in the number of NE cases in 2005. This 


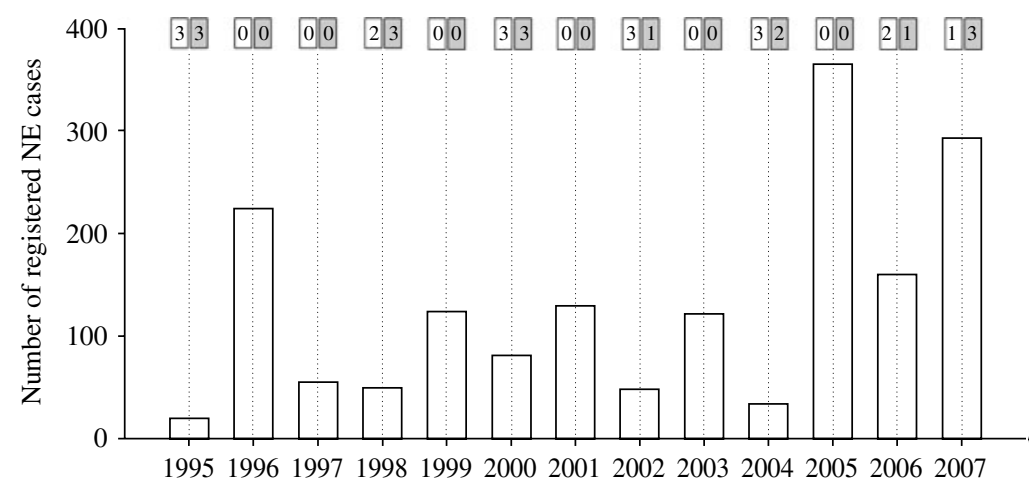

Fig. 1. Annual number of nephropathia epidemica (NE) cases and the category of seed production in the whole southern Belgian territory of beech, $F$. sylvatica (white boxes) and native oak, $Q$. robur and $Q$. petraea (grey boxes) in the respective years. Categories of fructification are ordered from 0 to $3(0=$ low, $1=$ moderate, $2=$ good, $3=$ very good $)$.

pattern of increased human infection did not cease in the following years, 160 cases were confirmed in 2006 and again 290 in 2007. Remarkably, as prior to 2005 , each epidemic year ( $>100$ NE cases annually) was followed by at least one non-epidemic year with $<60$ annual NE cases.

The categorical evaluation of annual beach and native oak fruiting in southern Belgium is indicated in Figure 1. We can observe that each peak year in NE incidence is preceded by a year with high seed production of at least native oak, beech or both. Separate analyses show a significant main effect of both beech $\left(F_{2,9}=9 \cdot 85, P=0 \cdot 007\right)$ and oak fruiting $\left(F_{3,8}=12 \cdot 79\right.$, $P=0.005)$. Very good or good seed production resulted in a significantly higher number of NE cases in the following year compared to low seed production for both beech $\left(0-2: \chi^{2}{ }_{1}=7 \cdot 67, P=0 \cdot 006 ; 0-3: \chi^{2}{ }_{1}=\right.$ $12 \cdot 37, P=<0 \cdot 001)$ and native oak $\left(0-1: \chi^{2}{ }_{1}=9 \cdot 68\right.$, $P=0.002 ; 0-2: \chi^{2}{ }_{1}=13 \cdot 11, P=<0 \cdot 001 ; 0-3: \chi_{1}^{2}=$ $7 \cdot 21, P=<0 \cdot 007)$. No significant differences were found among the higher seed production categories.

\section{Climate}

Only a limited number of significant explanatory variables were found. All showed a positive relationship to NE case numbers and most of the parameters are related to the summer season before tree seeding, i.e. 2 years before NE occurrence; summer temperature year $t-2\left(\chi_{1}^{2}=8 \cdot 01, P=0 \cdot 005\right)$; June-July temperature year $t-2 \quad\left(\chi_{1}^{2}=8.43, \quad P=0.004\right) ; \quad$ June temperature year $t-2\left(\chi^{2}{ }_{1}=4 \cdot 30, P=0.038\right)$. All of these parameters were correlated $(P<0 \cdot 01)$. Moreover, June temperature year $t-3$ was significant $\left(\chi_{1}^{2}=4 \cdot 76, P=0 \cdot 029\right)$. Additionally, we also found a significant effect of temperature during autumn, the
Table 1. Parameter estimates (log scale) of the best fitting model of annual nephropathia epidemica cases (year) and climate factors; average summer temperature year $-2\left({ }^{\circ} \mathrm{C}\right)$ and average autumn temperature year $-1\left({ }^{\circ} \mathrm{C}\right)$

\begin{tabular}{lrlll}
\hline \hline Parameter & Estimate & S.E. & $\chi^{2}$ & $P$ value \\
\hline Intercept & -12.577 & 2.286 & 30.28 & $<0.0001$ \\
$\begin{array}{l}\text { Autumn temp. } \\
\quad \text { year - 1) }\end{array}$ & 0.700 & 0.113 & 38.33 & $<0.0001$ \\
$\begin{array}{l}\text { Summer temp. } \\
\quad \text { year -2) }\end{array}$ & 0.421 & 0.075 & 31.72 & $<0.0001$ \\
\begin{tabular}{l} 
Deviance/D.F. \\
\hline \hline
\end{tabular} & 1.271 & & & \\
\hline
\end{tabular}

year preceding human case occurrence; autumn temperature year $t-1\left(\chi_{1}^{2}=5 \cdot 35, P=0 \cdot 021\right)$. The number of NE cases in year $t-1$ did not affect the NE cases in year $t$ significantly throughout the time-series $\left(\chi^{2}{ }_{1}=0 \cdot 01, P=0 \cdot 936\right)$. All combinations of significant independent parameters were made and the model with the lowest AIC value included summer temperature year $t-2$ and autumn temperature year $t-1$ $(\triangle \mathrm{AIC}>13)$ (Table 1, Figs 2, 3].

\section{DISCUSSION}

Our analyses show that regional homogeneous high seed production of both beech and native oak are closely related to increased numbers of NE cases in Belgium. These results, together with the known relationships between both bank vole abundance/high seed production and bank vole abundance/PUUV infection risk $[9,12,16,18,30]$, make us confident in stating that, if either beech, native oak or both show a very high seed production during autumn, this can be regarded as an early warning tool for public health 


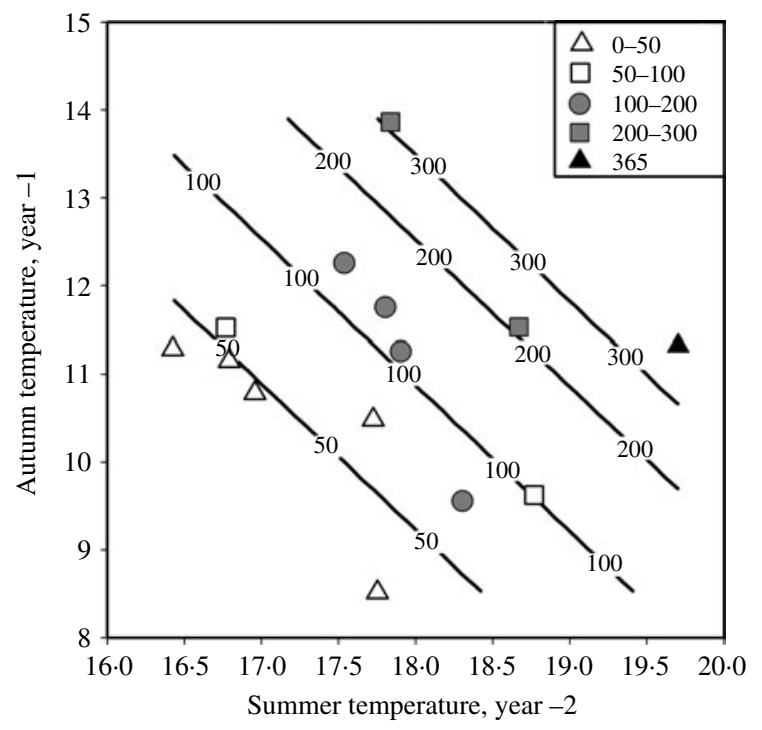

Fig. 2. Contour plot of the annual number of NE cases against the average summer temperature $\left({ }^{\circ} \mathrm{C}\right) 2$ years before and average autumn temperature $\left({ }^{\circ} \mathrm{C}\right) 1$ year before nephropathia epidemica (NE) infection. Contours are based on the selected model explained in Table 1. Intervals of raw NE data are given in the key.

workers. Centres like the Tree Seed Centre of the Walloon Region can therefore play a key role in alerting the IPH during the autumn seasons preceding NE outbreaks.

Furthermore, we gained insight in the ultimate processes changing NE epidemiology in Belgium and the rest of Western Europe. These processes seem to be directly related to climate. Although climate variables typically have a subtle or no measurable effect on disease systems, hantavirus infection has been shown to be very sensitive to climate variability [31]. There is the well known example of Sin nombre virus infection in the United States and its close link to increased precipitation patterns [32,33]. Even though it remains under discussion, a higher vegetation growth due to humid conditions causing increased resource availability would lead to higher deer mouse densities and a consequent higher infection risk. This process is known as the Trophic Cascade Hypothesis [34, 35]. Our system seems highly similar although other parameters link climate and human infection patterns. We found a significant effect of average autumn temperature 1 year before human infection occurrence. This finding is difficult to relate to tree seeding, during this period seeds fall from the trees. Higher temperatures from summer to autumn, however, have been related to increased bank vole reproduction. The underlying hypothesis here would be the importance

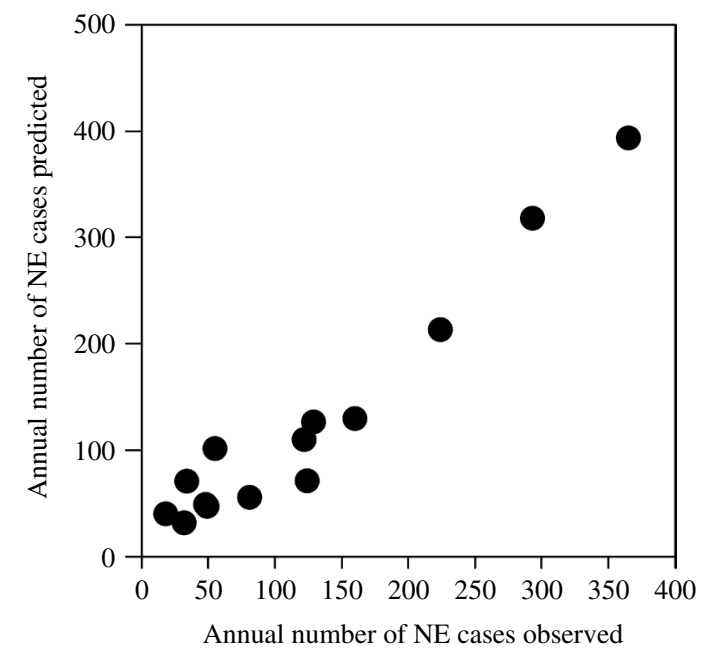

Fig. 3. Scatterplot of the observed vs. the predicted number of NE cases (year) by the selected model with average summer temperature (year - 2) and average autumn temperature (year -1$)$. Model details are given in Table 1 .

of green biomass and body condition. During the normal reproductive season, herbaceous plants constitute a high percentage of the bank vole diet. Normally green foliage decreases at the beginning of autumn, higher temperatures, however, can postpone this effect [17]. Furthermore, higher temperatures mean a lower use of resources to maintain the high metabolic rate of bank voles. The positive effect of average summer temperature in the 2 years preceding NE occurrence is directly related to the period of flower bud initiation in oak and beech. This is the one factor on which most studies agree that it is essential for good mast crops [26]. Therefore, higher temperatures during summer constitute an indirect link to higher PUUV infection risk and higher numbers of NE cases. Shorter mast year intervals and increasing mast crops have been observed in recent years [26]. The changing epidemiological cycles can thus be linked to these shorter intervals between masting and shorter intervals between more than average warm summers.

Finally, the warm summer temperatures could not only explain NE occurrence on a temporal scale, but also on a spatial scale. During 2003 an extreme climatic anomaly was registered in Europe. There was a summer heatwave with average summer temperatures exceeding the 1961-1990 mean by up to 5 S.D. and the summer might have been the warmest since 1540 [36]. This anomaly was most pronounced in West-Central Europe and affected local deciduous forests in Germany and part of France and Belgium [37]. Based 
on the findings in our study and observations, we therefore conclude that the extreme PUUV infection outbreak in 2005, which was most reported in those countries where the focus of the climate anomaly was found $[5,38]$, is a result of this heatwave occurring 2 years earlier in summer 2003. Based on the average temperature data of summer $2006\left(18.97^{\circ} \mathrm{C}\right)$ and autumn $2007\left(13.90^{\circ} \mathrm{C}\right)$, we again predict a very high number of NE cases in 2008; this seems to hold as during the first 5 weeks of 2008 already $30 \mathrm{NE}$ cases have been reported in Belgium (IPH).

High seed production by beech and native oak and elevated average summer temperatures followed by warmer autumn conditions in the next year should be considered as early warning indicators for NE outbreaks in Western Europe. The relationship with higher temperatures is especially valuable. Since future climate change scenarios predict higher temperatures in Europe, we suggest regarding PUUV as an increasing health threat.

\section{ACKNOWLEDGEMENTS}

We thank Stefan Van Dongen and Laurent Crespin from the University of Antwerp for help with the statistics. We thank two anonymous reviewers for their comments. K. Tersago works as an Academic Assistant at the University of Antwerp. This research was partially funded by EU grant GOCE-2003010284 EDEN and the paper is catalogued by the EDEN Steering Committee as EDEN0097 (http:// www.eden-fp6project.net/).

\section{DECLARATION OF INTEREST}

None.

\section{REFERENCES}

1. Woolhouse MEJ, Gowtage-Sequeria S. Host range and emerging and reemerging pathogens. Emerging Infectious Diseases 2005; 11: 1842-1847.

2. Vorou RM, Papavassiliou VG, Tsiodras S. Emerging zoonoses and vector-borne infections affecting humans in Europe. Epidemiology and Infection 2007; 135: 1231-1247.

3. Mills JN. Regulation of rodent-borne viruses in the natural host: implications for human disease. Archives of Virology (Suppl.) 2005; 19: 45-57.

4. Mailles A, et al. Larger than usual increase in cases of Hantavirus infections in Belgium, France and Germany, June 2005. Eurosurveillance 2005; 10: 198-200.
5. Heyman $\mathbf{P}$, et al. Haemorrhagic fever with renal syndrome: an analysis of the outbreaks in Belgium, France, Germany, the Netherlands and Luxembourg in 2005. Eurosurveillance 2007; 12: 15-16.

6. Vapalahti $\mathbf{O}$, et al. Hantavirus infections in Europe. Lancet Infectious Diseases 2003; 3: 653-661.

7. Heyman P, et al. Incidence of hantavirus infections in Belgium. Virus Research 2001; 77: 71-80.

8. Linard C, et al. Determinants of the geographic distribution of Puumala virus and Lyme borreliosis infections in Belgium. International Journal of Health Geographics 2007 ; 6: 15.

9. Olsson GE, et al. Human hantavirus infections, Sweden. Emerging Infectious Diseases 2003; 9: 1395-1401.

10. Linard C, et al. Environmental conditions and Puumala virus transmission in Belgium. International Journal of Health Geographics 2007; 6: 55.

11. Davis S, Calvet E, Leirs H. Fluctuating rodent populations and risk to humans from rodent-borne zoonoses. Vector Borne and Zoonotic Diseases 2005; 5: 305-314.

12. Escutenaire S, et al. Spatial and temporal dynamics of Puumala hantavirus infection in red bank vole (Clethrionomys glareolus) populations in Belgium. Virus Research 2000; 67: 91-107.

13. Sauvage F, Langlais M, Pontier D. Predicting the emergence of human hantavirus disease using a combination of viral dynamics and rodent demographic patterns. Epidemiology and Infection 2007; 135: 46-56.

14. Gavrilovskaya IN, et al. Pathogenesis of hemorrhagic fever with renal syndrome virus infection and mode of horizontal transmission of hantavirus in bank voles. Archives of Virology (Suppl.) 1990; 1: 57-62.

15. Yoccoz NG, et al. Effects of food addition on the seasonal density-dependent structure of bank vole Clethrionomys glareolus populations. Journal of Animal Ecology 2001; 70: 713-720.

16. Jensen TS. Seed production and outbreaks of noncyclic rodent populations in deciduous forests. Oecologia 1982; 52: 184-192.

17. Pucek Z, et al. Rodent population dynamics in a primeval deciduous forest (Bialowieza national park) in relation to weather, seed crop and predation. Acta Theriologica $1993 ;$ 38: 199-232.

18. Verhagen R, Leirs H, Verheyen W. Demography of Clethrionomys glareolus in Belgium. Polish Journal of Ecology 2000; 48: 113-123.

19. Crespin L, et al. Survival in fluctuating bank vole populations: seasonal and yearly variations. Oikos 2002; 98: 467-479.

20. Prévot-Julliard AC, et al. Delayed maturation in female bank voles: optimal decision or social constraint? Journal of Animal Ecology 1999; 68: 684-697.

21. Bujalska G, Saitoh T. Territoriality and its consequences. Polish Journal of Ecology 2000; 48: 37-49.

22. Clement $\mathbf{J}$, et al. Predicting hantavirus outbreaks and Lyme borreliosis peaks in Belgium-and Europe: of mast, mice and men. In: Abstracts of the 7th International Congress on Hantaviruses, Buenos Aires, Argentina, 13-15 June 2007, Abstract S1-O2, p. 21. 
23. Johnson PS, Shifley SR, Rogers R. The Ecology of Silviculture of Oaks. New York: CABI Publishers, 2002, pp. 61-64.

24. Koenig WD, Knops JMH. The mystery of masting in trees. American Scientist 2005; 93: 340-347.

25. Piovesan G, Adams JM. Masting behaviour in beech: linking reproduction and climatic variation. Botany 2001; 79: 1039-1047.

26. Övergaard R, Gemmel P, Karlsson M. Effects of weather conditions on mast year frequency in beech (Fagus sylvatica L.) in Sweden. Forestry 2007; 80: 555-565.

27. Kallio ER, et al. Prolonged survival of Puumala hantavirus outside the host: evidence for indirect transmission via the environment. Journal of General Virology 2006; 87: 2127-2134.

28. SAS Institute. SAS/STAT User's guide, version 9.1. SAS Institute Inc., Cary, 2003.

29. Agresti A. Categorical Data Analysis, 2nd edn, New Jersey: John Wiley \& Sons, 2002, pp. 324-325.

30. Clotfelter ED, et al. Acorn mast drives long-term dynamics of rodent and songbird populations. Oecologia 2007; 154: 493-503.

31. Tamerius JD, et al. Climate and human health: synthesizing environmental complexity and uncertainty. Stochastic Environmental research and Risk Assessment 2007; 21 : 601-613.
32. Engelthaler DM, et al. Climatic and environmental patterns associated with hantavirus pulmonary syndrome, Four Corners region, United States. Emerging Infectious Diseases 1999; 5: 87-94.

33. Hjelle B, Glass GE. Outbreak of hantavirus infection in the four corners region of the United States in the wake of the 1997-1998 El Nino-southern oscillation. Journal of Infectious Diseases 2000; 181: 1569-1573.

34. Yates TL, et al. The ecology and evolutionary history of an emergent disease: Hantavirus pulmonary syndrome. BioScience 2002; 52: 989-998.

35. Glass GE, et al. Persistently highest risk areas for hantavirus pulmonary syndrome: Potential sites for refugia. Ecological Applications 2007; 17: 129-139.

36. Zaitchik BF, et al. Europe's 2003 heat wave: a satellite view of impacts and land-atmosphere feedbacks. International Journal of Climatology 2006; 26: 743-769.

37. Reichstein M, et al. Reduction of ecosystem productivity and respiration during the European summer 2003 climate anomaly: a joint flux tower, remote sensing and modelling analysis. Global Change Biology 2007; 13: 634-651.

38. Abu Sin M, et al. Risk factors for hantavirus infection in Germany, 2005. Emerging Infectious Diseases 2007; 13: 1364-1366. 